Clarke, M, Broughton, J, Hutchinson, A and Buckley, M

Application of the design of experiments procedure to the behaviour of adhesively bonded joints with plastically deformable adherends to enable further understanding of strain rate sensitivity.

International Journal of Adhesion and Adhesives, 2013, 44 (July). pp. 226-231.

DOI : 10.1016/j.ijadhadh.2013.03.003

This version is available: http://radar.brookes.ac.uk/radar/preview/7b1a99e7-4943-421a-32c9-c8a0fbac66ea/1/

Available on RADAR: May 2013

Copyright (C) and Moral Rights are retained by the author(s) and/ or other copyright owners. A copy can be downloaded for personal non-commercial research or study, without prior permission or charge. This item cannot be reproduced or quoted extensively from without first obtaining permission in writing from the copyright holder(s). The content must not be changed in any way or sold commercially in any format or medium without the formal permission of the copyright holders.

This document is the author's final version of the journal article. Some differences between the published version and this version may remain and you are advised to consult the published version if you wish to cite from it. 


\title{
Application of the Design of Experiments procedure to further understanding of the strain-rate sensitivity of adhesively bonded joints with plastically deformable adherends
}

\author{
M.I. Clarke ${ }^{1 *}$ J.G. Broughton ${ }^{1}$, A.R. Hutchinson ${ }^{1}$, M. Buckley ${ }^{2}$ \\ 1. Faculty of Technology, Design and Environment, Oxford Brookes University, Oxford, UK \\ 2. Jaguar Land Rover, Gaydon, UK
}

\begin{abstract}
The study presented in this paper was carried out to investigate further the effects of strain rate on the strength of adhesively bonded single lap shear joints. Tests were carried out on two different configurations of adhesively bonded joints that were designed to exhibit different behaviours. In one configuration both adherends were made from a relatively low strength grade of aluminium such that both would exhibit significant plastic deformation prior to adhesive failure. The other configuration used one adherend that was significantly stronger such that only elastic deformation was exhibited prior to failure of the adhesive. The joint specimens were tested at several different strain rates using a servo-hydraulic test machine and the results analysed using statistical methods. To further understand the results Finite Element models of the joints were created using a Cohesive Zone Model to predict damage development and failure in the adhesive. The Design of Experiments procedure was used to study the effects of material parameters relating to both the adherends and the adhesive in the Finite Element models. The results of the testing suggested that the strength of joints formed from two adherends that exhibited plastic deformation prior to failure did not show statistically significant sensitivity to strain rate. Interpretation of the results of the Finite Element analyses suggested that the adherend yield was the main factor influencing failure in the adhesive for joints of this type.
\end{abstract}

Keywords: lap-shear, aluminium and alloys, impact, finite element stress analysis, design of experiments

\section{List of Symbols}

$\Gamma_{\mathrm{I}}, \Gamma_{\mathrm{II}}-$ Interface toughness in Mode I and Mode II respectively

$\hat{\sigma}_{I}, \hat{\sigma}_{I I}-$ Peak interface stress in Mode I and Mode II respectively

$\mu$ - Arithmetic mean

E - Young's Modulus

$\mathrm{mm}$ - millimetre

$\mathrm{m} \cdot \mathrm{s}^{-1}-$ metre per second

${ }^{\circ} \mathrm{C}$ - degree Celsius

$\mathrm{H}_{0}-$ Null Hypothesis

\footnotetext{
* Corresponding author. Current address: Joining Technology Research Centre, Oxford Brookes University, Wheatley Campus, Wheatley, Oxfordshire, OX33 8HX, UK. Tel.: +44 (0)1865483510

E-mail address: matt.clarke@brookes.ac.uk
} 


\section{Background}

A significant difficulty in the use of adhesives is that, in general, their behaviour is visco-elastic and hence sensitive to strain rate and temperature. Unfortunately for the engineer wishing to study the behaviour of adhesives under high strain rate loading there are few standard test methods available. Some authors have therefore adopted standard test methods developed for obtaining quasi-static properties and applied the loading at high rate. This method has been used to measure adhesive properties in bulk form $[1,2]$ and also to characterise the fracture behaviour under varying loading rates $[3,4]$. The general conclusion from these studies is that as rate of loading increases the strength of an adhesive increases and toughness decreases, which is consistent with established models for visco-elastic materials.

Another frequently adopted approach is the study of bonded assemblies that are representative of a particular application. A typical example of this approach is the use of axially loaded box sections as a means to investigate the behaviour of energy absorbing structures for automotive applications, which have been the subject of several studies in the literature $[5,6,7]$. The difficulty presented by the use of such structures is that the results are influenced heavily by factors extrinsic to the adhesively bonded joints, leading to difficulties in drawing general conclusions regarding the effect of rate of loading. Furthermore the bonded specimens and loading apparatus can be costly, which generally limits the number of replicate tests that can be undertaken.

To investigate more thoroughly the behaviour of adhesively bonded joints under high strain rate conditions several authors have studied the behaviour of lap shear joints $[2,8,9,10,11]$. Interestingly, there is a lack of consensus in the literature as to the effect of strain rate on the behaviour of joint specimens. Some authors concluded that the joint strength was not sensitive to strain rate, others that rate sensitivity is observable. In addition to physical testing, Finite Element Analysis has been used extensively to investigate the behaviour of adhesively bonded. A comprehensive review of the subject is considered to be outside the scope of the present study but can be found in the literature [12]. This review discusses a number of methods used for analysing adhesively bonded joint and notes the application of the Cohesive Zone Model to such analyses. The Cohesive Zone Model was developed for modelling crack growth in monolithic materials, as described by Pandya et al. [13, 14]. Application of the Cohesive Zone Model to adhesively bonded joints has been described by several authors for predicting damage due to quasi-static, impact and fatigue loading $[15,16,17]$; and environmental degradation [18]. In the present study a combination of experimental methods and Finite Element Analysis using a Cohesive Zone Model were used to investigate the effect of strain rate on the behaviour of single lap shear joints formed from aluminium and a high strength, toughened adhesive.]. The Cohesive Zone Model parameters used are discussed in further detail in Section 3.1 and have also been described fully in previously published studies [19, 20].

\section{Experimental Work}

\subsection{Test Programme}

To investigate the effect of adherend behaviour on the strength of joints, two different lap shear joint configurations were tested. The material described as "Plastic" was selected such that it would yield prior to failure of the adhesive in an adhesively bonded lap shear joint. Conversely, the "Elastic" material was selected such that only elastic deformation would occur. Details of materials used for the "Elastic" and "Plastic" adherend types are given in Table 1. The adhesive in both cases was XD4601, a single component heat curing toughened epoxy used in the automotive industry [21].

\begin{tabular}{ccccccc}
\hline Adherend Type & Material & Thickness $(\mathrm{mm})$ & Surface Condition & $\mathrm{E}(\mathrm{GPa})$ & $\sigma_{\mathrm{y}}(\mathrm{MPa})$ & $\varepsilon_{\text {fail }}(\%)$ \\
\hline Plastic & AA5754 & 1.5 & PT2 [22] & 70 & $80(\mathrm{~min})$. & 16 \\
\hline Elastic & AA2014-T6 & 2.5 & Clad & 70 & $380(\mathrm{~min})$. & 7 \\
\hline
\end{tabular}

Table 1 Specifications and properties [23] of adherend materials 
The programme of tests carried out is shown in Table 2. The "Fully Plastic" joint configuration used two adherends of the Plastic type defined in Table 1. Conversely the "Unbalanced" joint configuration used one Plastic and one Elastic adherend. The highest speed of $2 \mathrm{~m} \bullet \mathrm{s}^{-1}$ was chosen as the highest speed at which the force could be measured accurately with the load cell in the test machine. Above this speed the load signal was affected by superimposed oscillations that led to difficulties in interpreting results. The two lower test speeds were chosen at decreasing orders of magnitude from the highest test speed.

\begin{tabular}{lcccc}
\hline & Test Speed $\left(\mathrm{m}^{-1} \mathrm{~s}^{-1}\right)$ & 0.01 & 0.1 & 2.0 \\
\cline { 2 - 5 } & & \multicolumn{3}{c}{ Number of Tests } \\
\hline \multirow{2}{*}{ Joint Configuration } & Fully Plastic & 5 & 5 & 5 \\
\cline { 2 - 5 } & Unbalanced & 5 & 5 & 5 \\
\hline
\end{tabular}

Table 2 Test matrix for high strain rate tests

\subsection{Test Procedure}

An Instron VHS160/100-20 servo-hydraulic test machine was used to achieve the necessary test speeds. The test machine was equipped with a lost motion system that allowed for the test machine crosshead to achieve the required test speed before the load is applied to the test specimen. Due to the operation of the lost motion system modifications were required to the standard lap joint described in BS EN 1465 [24] in that the length of the adherends was increased to allow for the lost motion prior to loading of the specimens. However, details of the adhesively bonded overlap area were kept as described in BS EN 1465. The development of a suitable test specimen is discussed in [19].

The test specimens were manufactured using the procedure described in BS EN 1465, in which panels of sufficient width for several specimens are bonded together and then cut to width to give individual specimens. The surfaces of the aluminium were treated using a solvent wipe with acetone immediately prior to bonding. The adhesive was then spread into place and a small quantity of $250 \mu \mathrm{m}$ ballotini added to control the bondline thickness. The assembly was then cured at $180^{\circ} \mathrm{C}$ for 50 minutes. A horizontal milling machine, fitted with a slitting saw, was used to cut the individual specimens, taking care to limit heat generated in the specimens due to cutting.

The specimens were loaded into the test machine in a manner that ensured that the lost motion system did not prematurely load the specimen. The test procedure was then initiated from a PC that controlled the test machine. The control PC software also incorporated data acquisition that recorded specimen load and extension derived from crosshead position. These data were recorded for each test.

\subsection{Test Results}

The adherend materials showed a strong influence on the recorded data for load and position. It was concluded that, for a particular joint configuration, load and extension are not independent variables and therefore meaningful analysis could be conducted using one parameter only. Given the inherent inaccuracy in extension data derived from crosshead position it was decided to analyse the load data. These data were plotted in the form of test speed versus peak force for each of the three joint configurations, as shown in the Figures below.

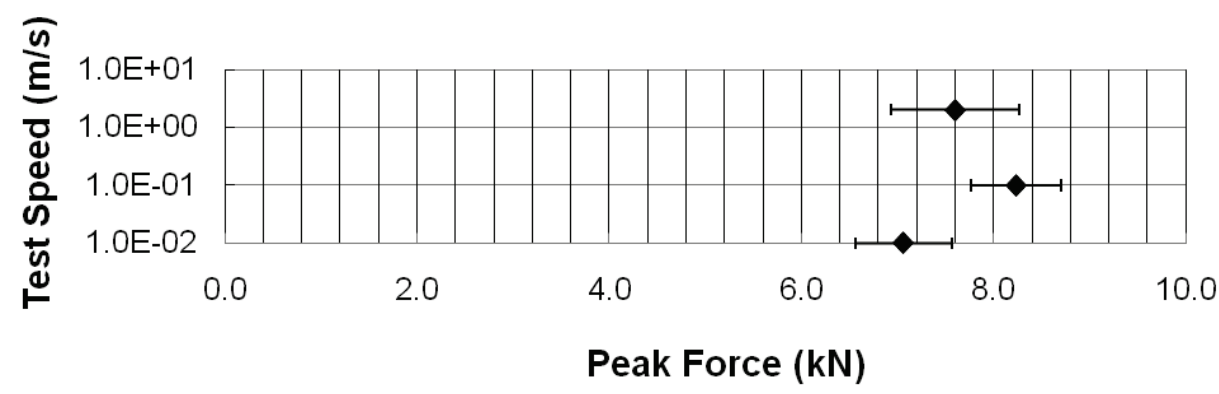

Figure 2.1 Test speed against peak force results for Fully Plastic joint configuration 


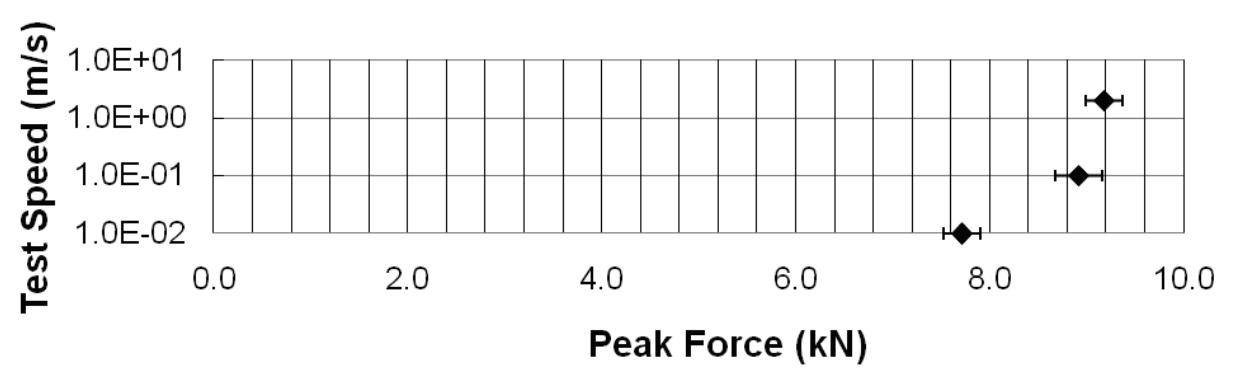

Figure 2.2 Test speed against peak force results for Unbalanced joint configuration

\subsection{Statistical Analysis of Test Results}

In conducting analysis of the test results it was considered important to define exactly what was to be established from the analysis. As already discussed, several authors $[8,9,10]$ have reported on testing of adhesively bonded joints and concluded that the strength was not significantly affected by strain rate. In the present study this suggestion was to be investigated further using the test data obtained. A formal statement of the question that was to be answered was formulated as:

Is the mean strength for a particular joint configuration significantly affected by the test speed?

In order to answer this question the following null hypothesis $\left(\mathrm{H}_{0}\right)$ was proposed:

$$
\mathrm{H}_{0}: \mu_{\mathrm{v} 1}=\mu_{\mathrm{v} 2}
$$

where the subscripts $\mathrm{v} 1$ and $\mathrm{v} 2$ refer to different test speeds.

In this hypothesis $\mu_{0.01}, \mu_{0.1}, \mu_{2}$ are the mean strengths of the sample of a particular joint configuration when tested at $0.01,0.1$ and $2 \mathrm{~m} \bullet \mathrm{s}^{-1}$ respectively. The null hypothesis was tested using Welch's t-test, which assumes that the samples being compared are normally distributed, but does not assume equal variance. The t-test calculations were carried out automatically using the analysis toolbox in Microsoft Excel and the results are shown in Table 3.

\begin{tabular}{cccccc}
\hline $\begin{array}{c}\text { Specimen } \\
\text { Configuration }\end{array}$ & $\begin{array}{c}\text { Null Hypothesis } \\
\mathrm{H}_{0}\end{array}$ & $\mathrm{t}$ stat & $\mathrm{t}_{\text {crit }}(5 \%)$ & $\mathrm{t}_{\text {crit }}(1 \%)$ & Conclusion \\
\hline \multirow{2}{*}{ Fully Plastic } & $\mu_{2}=\mu_{0.1}$ & 12.51 & 2.262 & 3.25 & $\begin{array}{c}\text { Reject } \mathrm{H}_{0} \text { at } 1 \% \\
\text { level }\end{array}$ \\
\cline { 2 - 5 } & $\mu_{0.1}=\mu_{0.01}$ & 9.520 & 2.228 & 3.17 & $\begin{array}{c}\text { Reject } \mathrm{H}_{0} \text { at } 1 \% \\
\text { level }\end{array}$ \\
\hline Unbalanced & $\mu_{2}=\mu_{0.1}$ & 1.341 & 2.571 & 4.03 & Accept $\mathrm{H}_{0}$ \\
\cline { 2 - 5 } & $\mu_{0.1}=\mu_{0.01}$ & 1.649 & 2.571 & 4.03 & Accept $\mathrm{H}_{0}$ \\
\hline
\end{tabular}

Table 3 Summary of results from t-tests

It was concluded that the null hypothesis could be rejected at the $1 \%$ confidence level between $2 \mathrm{~m} \cdot \mathrm{s}^{-1}$ and $0.1 \mathrm{~m} \cdot \mathrm{s}^{-1}$; and between $0.1 \mathrm{~m} \cdot \mathrm{s}^{-1}$ and $0.01 \mathrm{~m} \cdot \mathrm{s}^{-1}$ for the Unbalanced joints, as shown in Table 3 . It was not possible to reject the null hypothesis for either test for the Fully Plastic joint configuration. These conclusions appear reasonable from inspection of Figures 2.1 and 2.2 above. 


\section{Experimental Matrix and Sensitivity Study on Finite Element Model}

\subsection{Finite Element Model}

A Finite Element model of the lap joints was created using Abaqus/CAE [25]. Type S4R shell elements were used to model the aluminium adherends with solid elements to represent the adhesive layer. This approach can result in the issue that the thickness of the adhesive elements must be increased from the actual value due to the thickness of shell elements being zero. Various approaches have been used to correct for this issue, such as the use of spring elements to connect from the shell elements to the adhesive surface or corrections to the material properties [26]. In the present study the offset parameters SPOS and SNEG, shown in Figure 3.1, were used to specify that the shell elements represented the bonding surface of the adherends rather than the mid-plane. The adhesive was modelled using Abaqus type COH3D8 8-node cohesive elements. A mesh plot is shown in Figure 3.2. It can be seen that the in-plane dimensions of the adhesive elements are larger than is often recommended. However, previously published convergence studies [20] showed an acceptable level of accuracy with such element sizes when compared with test data for the same joint configuration.

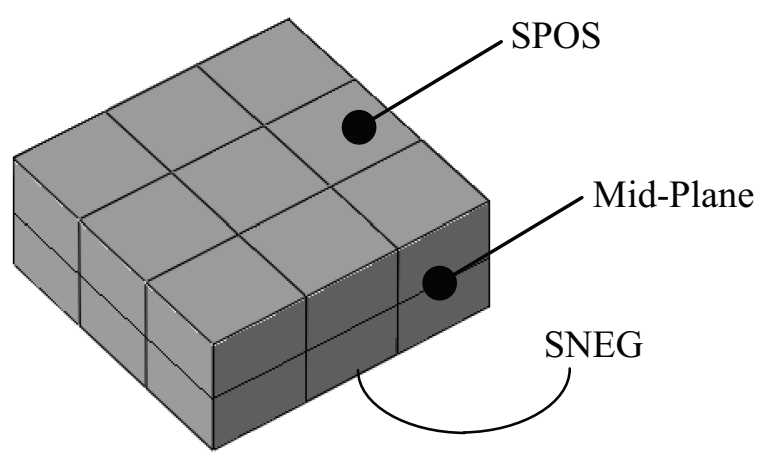

Figure 3.1 Shell element surface offset definitions

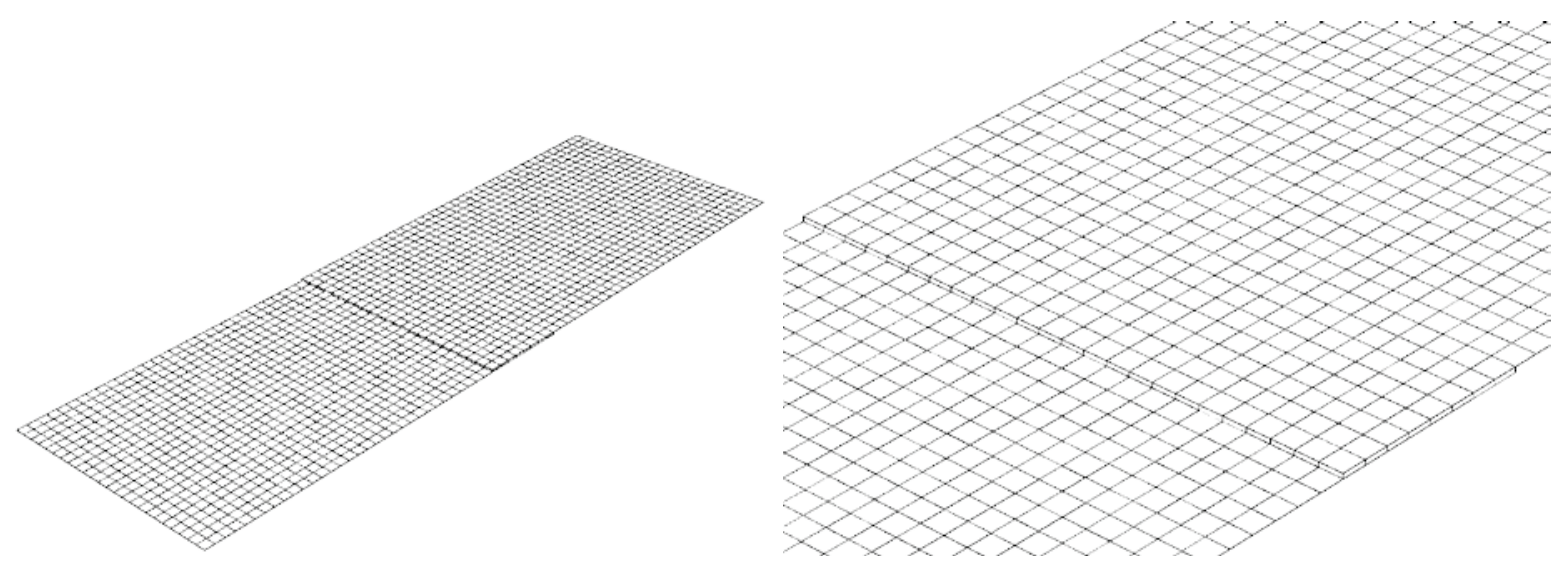

Figure 3.2 Finite Element mesh plots for single lap shear joints 
A Traction-Separation law of the form shown in Figure 3.3 was specified for the adhesive elements. Two parameters were used to specify Traction-Separation laws for Mode I and Mode II loading. The onset of failure was governed by peak interface stresses $\hat{\sigma}_{\mathrm{I}}$ and $\hat{\sigma}_{\mathrm{II}}$ for Mode I and Mode II respectively. After onset of failure the adhesive stiffness was degraded linearly according to energy based failure criteria, with the failure energy described by parameters $\Gamma_{\mathrm{I}}$ and $\Gamma_{\mathrm{II}}$ for Mode I and Mode II respectively. Mixed mode behaviour of the adhesive was described by a quadratic combination of the pure Mode I and Mode II responses, giving the elliptical failure envelope shown in Figure 3.3. This model, in the context of adhesively bonded lap joints, has been described previously and shown to represent the physical test specimens with acceptable accuracy [20].

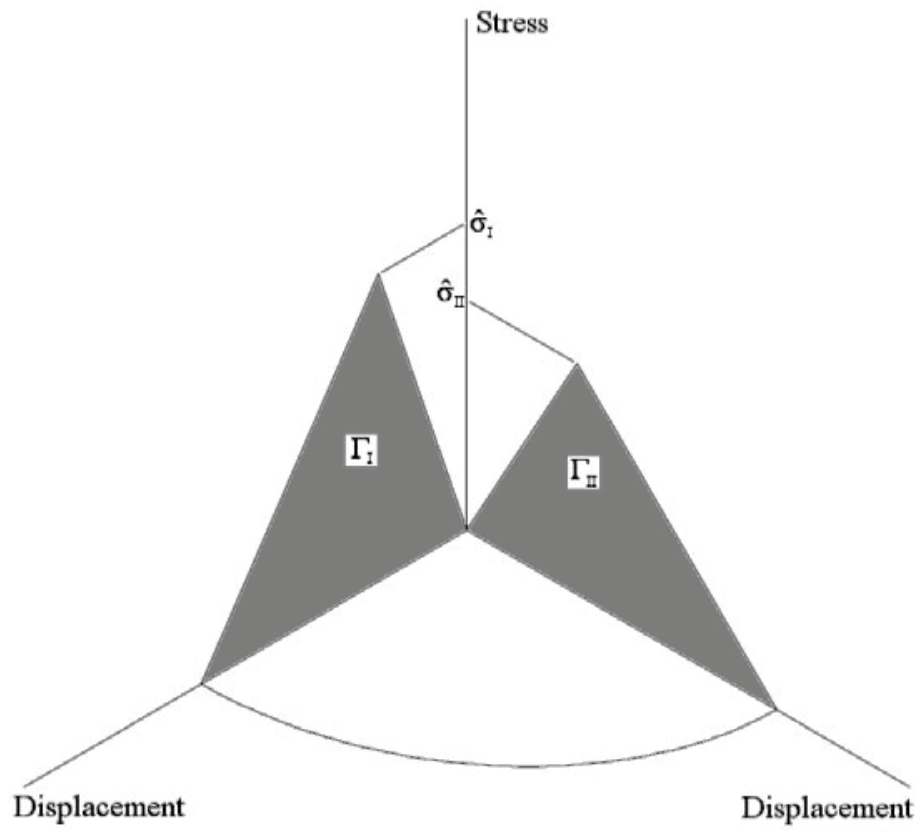

Figure 3.3 Adhesive parameters specified in Traction-Separation Law

The aluminium material properties for AA5754 were modelled using the elastic and plastic material options within Abaqus/CAE. An idealised, bi-linear elastic-plastic stress-strain behaviour, as shown in Figure 3.4, was specified to allow for parametric input. For AA2014-T6 only elastic properties were specified since no yielding was observed in the physical tests.

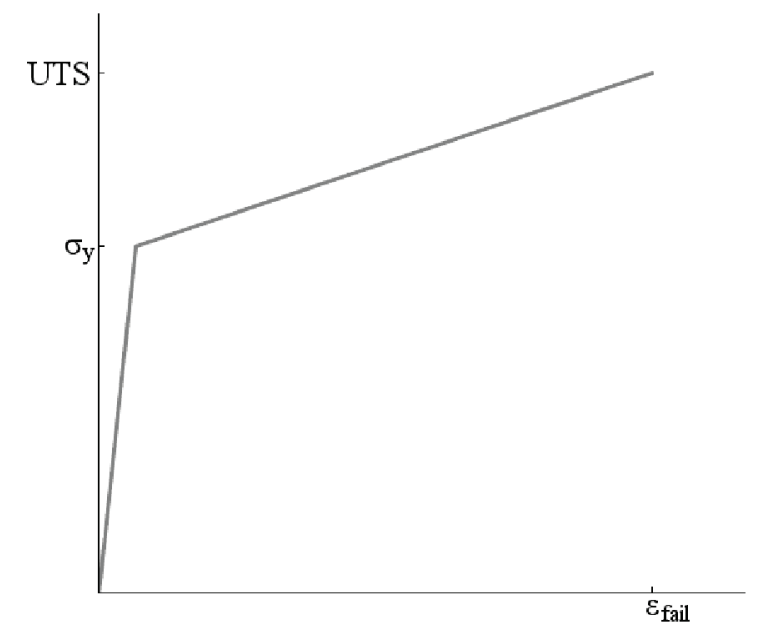

Figure 3.4 Simplified stress-strain input for AA5754 


\subsection{Analysis Input Experimental Matrix}

The Finite Element model was used by creating a script to modify systematically the material properties in accordance with a two level experimental matrix. The high and low input parameters were chosen as approximately $\pm 10 \%$ of the experimentally determined values and are shown in Table 4 and Table 5. A full factorial experiment would have resulted in 128 individual analyses and therefore a reduced factorial matrix was selected. It was decided to use a partial factorial design to limit the number of individual analyses to 32. A suitable experimental design published by NIST/SEMATECH [27] was selected. Whilst this represents a substantial reduction in computational expense it still eliminates confounding of main effects with second order interactions. It was considered that false interpretation of the results due to confounding of main effects with third order interactions represented a sufficiently small risk that the experimental design selected was justifiable.

\begin{tabular}{cccccc}
\cline { 2 - 6 } & $\mathrm{E}(\mathrm{GPa})$ & $\hat{\sigma}_{\mathrm{I}}(\mathrm{MPa})$ & $\Gamma_{\mathrm{I}}\left(\mathrm{J}^{\circ} \mathrm{m}^{-2}\right)$ & $\hat{\sigma}_{\text {II }}(\mathrm{MPa})$ & $\Gamma_{\mathrm{II}}\left(\mathrm{J} \bullet \mathrm{m}^{-2}\right)$ \\
\hline High value & 3.1 & 50 & 3100 & 40 & 3700 \\
\hline Low value & 3.7 & 60 & 3700 & 48 & 4500 \\
\hline
\end{tabular}

Table 4 Input values for adhesive Cohesive Zone Model

\begin{tabular}{cccc}
\cline { 2 - 4 } & \multicolumn{3}{c}{ Parameter } \\
\cline { 2 - 4 } & $\sigma_{\mathrm{y}}(\mathrm{MPa})$ & $\sigma_{\max }(\mathrm{MPa})$ & $\varepsilon_{\text {fail }}$ \\
\hline High value & 100 & 300 & 0.27 \\
\hline Low value & 120 & 380 & 0.33 \\
\hline
\end{tabular}

Table 5 Input values for AA5754 adherend material

\subsection{Results from Finite Element Analyses}

The results from the Finite Element analyses were processed by extracting predicted joint strength for each analysis. From these data mean joint strengths with high and low inputs for each parameter were calculated. These results are shown graphically as DoE mean plots in Figures 3.5 and 3.6. In both cases the figures show the effects of all parameters in the left hand graph and effects for adhesive parameters only in the right hand graph. The magnitude of the gradient indicates the significance of the parameter on the calculated joint strength in that a higher gradient shows greater significance. These results are discussed further in Section 4.
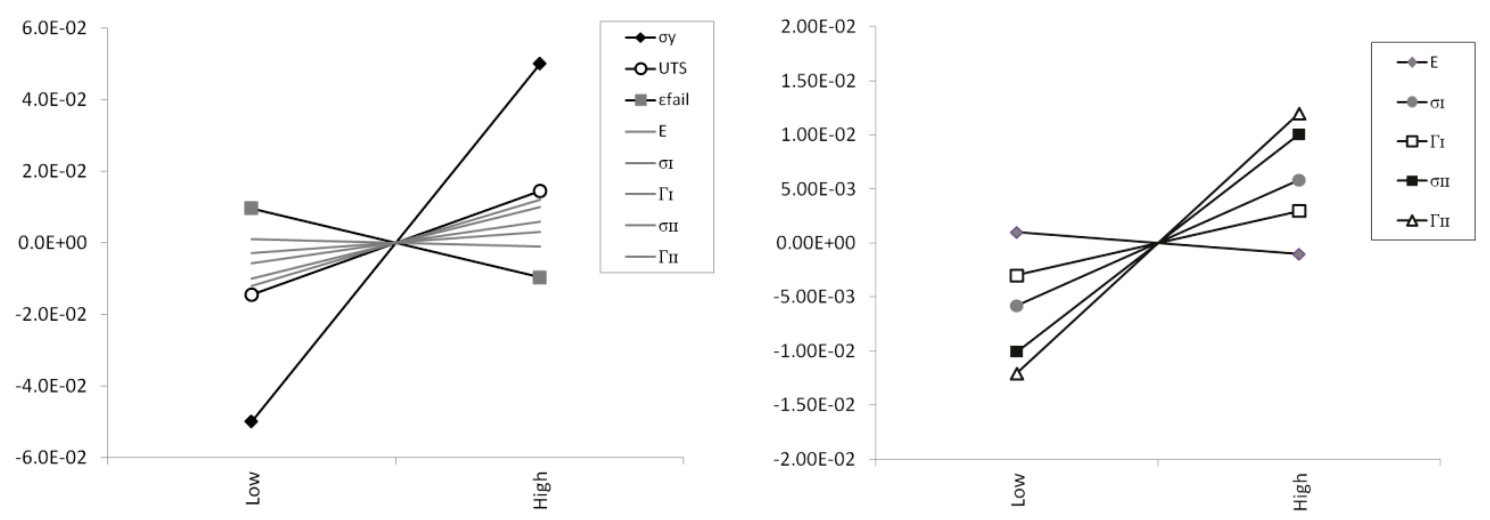

Figure 3.5 Sensitivity of F.E. model (Fully Plastic configuration) to all DoE parameters (left) and adhesive only properties (right) 

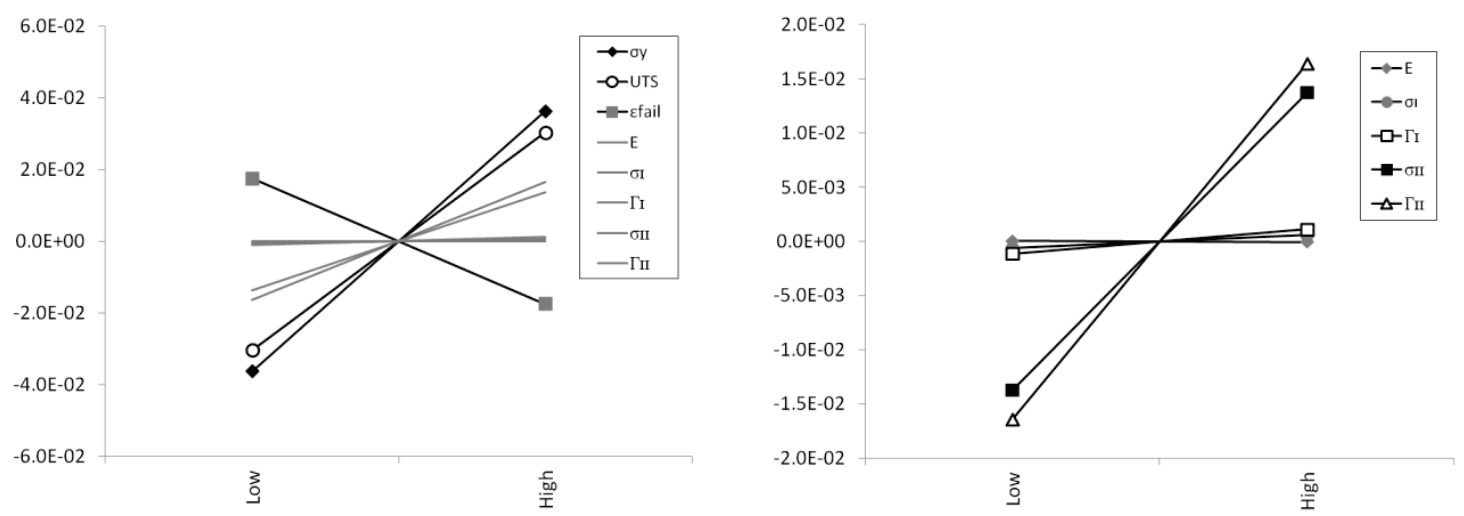

Figure 3.6 Sensitivity of F.E. model (Unbalanced configuration) to all DoE parameters (left) and adhesive only properties (right)

It was noted in Section 3.2 that, due to the experimental design used, the main effects were confounded with third order effects. Whilst the risk of false interpretation of results was considered to be small it was decided, nonetheless, to investigate the confounding structure further. The confounding of main effects with third order effects is defined in Table 6. Following inspection of the results shown in Table 6 it was considered reasonable to conclude that observed effects are due to the main effect rather than three factor interactions. The only exception to this may be for $\Gamma_{\mathrm{I}}$, which is confounded with the three parameters relating to the adherend material. However, reference to Figures 3.5 and 3.6 shows that the sensitivity of results to $\Gamma_{\mathrm{I}}$ is relatively low. It is, therefore, considered that incorrect interpretation of the results due to confounding is unlikely.

\begin{tabular}{ccc}
\hline Parameter & Confounding 1 & Confounding 2 \\
\hline$\sigma_{\mathrm{y}}$ & $\sigma_{\max }{ }^{*} \varepsilon_{\text {fail }}{ }^{*} \Gamma_{\mathrm{I}}$ & $\sigma_{\max }{ }^{*} \mathrm{E}^{*} \hat{\sigma}_{\mathrm{II}}$ \\
\hline$\sigma_{\max }$ & $\sigma_{\mathrm{y}}{ }^{*} \varepsilon_{\text {fail }}{ }^{*} \Gamma_{\mathrm{I}}$ & $\sigma_{\mathrm{y}}{ }^{*} \mathrm{E}^{*} \hat{\sigma}_{\mathrm{II}}$ \\
\hline$\varepsilon_{\mathrm{fail}}$ & $\sigma_{\mathrm{y}}{ }^{*} \sigma_{\max }{ }^{*} \Gamma_{\mathrm{I}}$ & $\mathrm{E}^{*} \Gamma_{\mathrm{I}}{ }^{*} \hat{\sigma}_{\mathrm{II}}$ \\
\hline $\mathrm{E}$ & $\sigma_{\mathrm{y}}{ }^{*} \sigma_{\max }{ }^{*} \hat{\sigma}_{\mathrm{II}}$ & $\varepsilon_{\text {fail }}{ }^{*} \Gamma_{\mathrm{I}}{ }^{*} \hat{\sigma}_{\mathrm{II}}$ \\
\hline$\Gamma_{\mathrm{I}}$ & $\sigma_{\mathrm{y}}{ }^{*} \sigma_{\max }{ }^{*} \varepsilon_{\text {fail }}$ & $\varepsilon_{\text {fail }}{ }^{*} \mathrm{E}^{*} \hat{\sigma}_{\mathrm{II}}$ \\
\hline$\hat{\sigma}_{\mathrm{II}}$ & $\sigma_{\mathrm{y}}{ }^{*} \sigma_{\max }{ }^{*} \mathrm{E}$ & $\varepsilon_{\text {fail }}{ }^{*} \mathrm{E}^{*} \Gamma_{\mathrm{I}}$ \\
\hline
\end{tabular}

Table 6 Confounding structure for experimental design

\section{Discussion}

As was discussed in the introduction, there is some debate in the literature as to the effect of varying strain rate on the properties of adhesively bonded joints. Several authors have noted a limited effect of strain rate on the properties of adhesively bonded single lap shear joints. This conclusion was reached following tests carried out on joints formed with relatively thin adherends where adherend yield occurred before failure. Based on the results from the statistical analysis presented in Section 2 it would be reasonable to conclude that with joints of this type the conclusion of no change in strength is in agreement with the results of the present study. Conversely, the Unbalanced joints did display statistically significant variation in joint strength with strain rate. Investigation of the sensitivity studies summarised in Figures 3.5 and 3.6 shows that the adhesive parameters $\Gamma_{\text {II }}$ and $\widehat{\sigma}_{\text {II }}$ have a greater effect on the calculated joint strength for the Unbalanced configuration than the Fully Plastic configuration. Figure 4.1 shows the relevant parameters and illustrates the relative sensitivities more clearly. This increased sensitivity to the adhesive parameters may explain the apparent rate sensitivity in one configuration and not the other. 

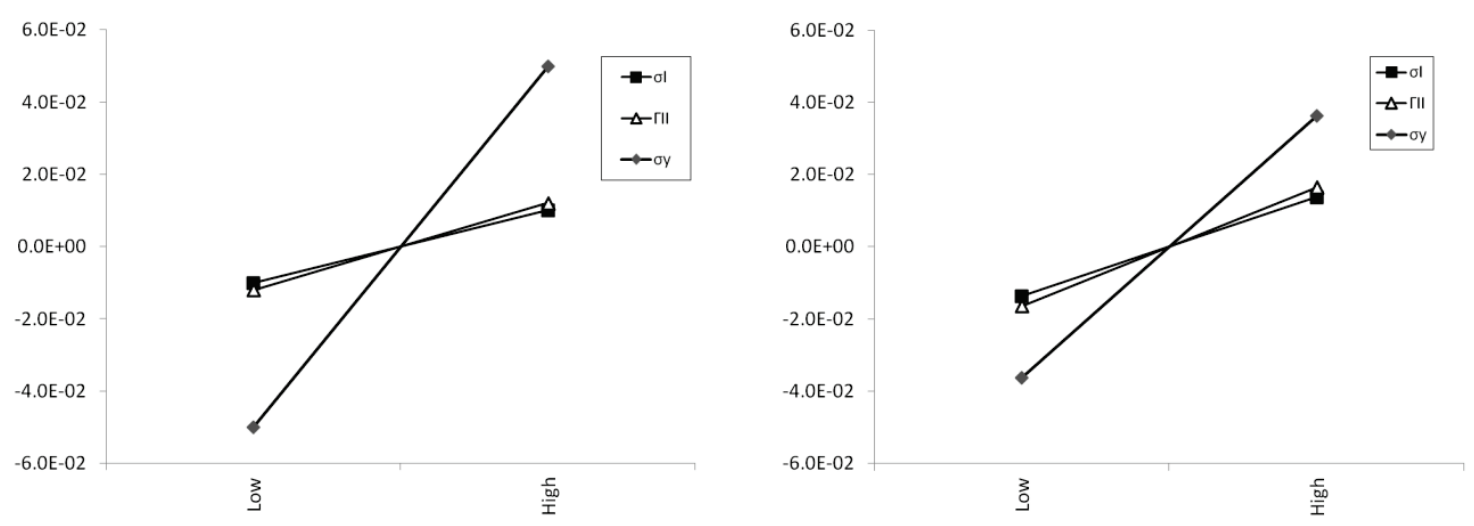

Figure 4.1 DoE mean plots of adhesive parameters $\Gamma_{\text {II }}$ and $\widehat{\sigma}_{\text {II }}$ for Unbalanced (left) and Fully Plastic (right) joint configurations

Comparison of the results shows that the adherend yield stress has a more significant effect compared with the adherend UTS for the Fully Plastic configuration (Figure 3.5) than the Unbalanced configuration (Figure 3.6). These parameters effectively control the strain hardening behaviour of the adherend materials. The relative sensitivities of these parameters tend to support the suggestion that, for joints with high strength, toughened adhesives where significant plastic deformation of the adherends occurs, the failure process is strongly influenced by adherend yield. Again, this supports the suggestion that for bonded joints of this type the strength is not significantly influenced by visco-elastic effects in the adhesive.

A difficulty with conducting analyses of adhesively bonded joints under high strain rate loading is the lack of published standards for measuring adhesive properties under high strain rate conditions. From the conclusions above it reasonable to suggest that, for a first approximation, it may be practical to use materials data obtained from quasi-static tests in simulations of bonded structures subjected to high rates of loading if significant yield and plastic deformation of the bonded components occurs prior to failure of the adhesive. In this case the degree of error involved may well be acceptable for basic analyses to screen alternative designs. Where connections are made to components that are stronger and deform only elastically prior to failure of the adhesive the results may be somewhat less reliable.

The sensitivity studies showed that, for both joint configurations analysed, the parameters that most affected joint behaviour related to the adherends. Whilst this observation may appear obvious it serves to emphasise that accurate analysis of adhesively bonded joints requires accurate models of the adherends. For joint systems where high strength structural adhesives are used this is not trivial as the adherends may well experience substantial deformation and damage processes prior to joint failure. In more complex bonded structures the effects of boundary conditions may add further demands. The Design of Experiments procedure used in the present study appears to be a useful screening procedure to assist with understanding of the results of tests on specimens where significant deformation and damage occurs in the adherends. 


\section{Conclusions}

The empirical evidence suggests that the strength of single lap shear lap joints where both adherends deform plastically prior to failure is not significantly affected by the test speed. Based on evidence from the Design of Experiments study it is suggested that, for joints of this type, adherend yield has a more significant effect on failure behaviour than the adhesive properties. The experimental work suggested that statistically significant changes in strength were caused by varying strain rate for single lap shear joints where one adherend underwent only elastic deformation prior to adhesive failure. Analysis of the results of Design of Experiments showed significant effects relating to adhesive parameters compared with the adherend parameters. Whilst adherend yield was still the dominant term the shear properties of the adhesive were a more significant influence than was the case for joints where both adherends exhibited significant plastic deformation prior to adhesive failure.

In general, the Design of Experiments procedure applied to multiple Finite Element Analyses provides a useful method for studying the effects of large numbers of parameters on the results of investigations.

\section{Acknowledgements}

The authors would like to thank Jaguar Land Rover Research and the Engineering and Physical Sciences Research Council (EPSRC) for financial support for the experimental work described. Further acknowledgement is given to the University of Warwick for providing high strain rate testing facilities.

The authors also gratefully acknowledge the Technology Strategy Board (TSB) for funding the parametric scripting work through the Advanced Composite Truss Structures (ACTS) project.

\section{References}

[1] Goda, Y and Sawa. Study on the effect of strain rate of adhesive material on the stress state in adhesive joints, J. Adhesion. 87 (2011) 766-779

[2] Zgoul, $\mathrm{M}$ and Crocombe, A.D. Numerical modelling of lap joints bonded with a rate-dependent adhesive. Int. J. of Adhesion and Adhesives. 24 (2004) 355-366.

[3] Karac, A, et al. Modelling the fracture behaviour of adhesively-bonded joints as a function of test rate, Eng. Fract. Mech. 78 (2011) 973-989.

[4] Raghavan, D, et al. Strain rate dependance of fracture in rubber-toughened epoxy system. J. of Adhesion. 78 (2002) 723-739.

[5] Fay, P.A and Suthurst, G.D. Redesign of adhesively bonded box beam sections for improved impact performance. Int. J. of Adhesion and Adhesives. 10 (1990) 128-138.

[6] Avalle, M, et al. Bi-material joining for car body structures: experimental and numerical analysis. J. of Adhesion. 86 (2010) 539-560.

[7] McGregor, I.J., Seeds, A.D. and Nardini, D. The design of impact absorbing members for aluminum structured vehicles. SAE Technical Paper Series, (1990) 900796.

[8] Beevers, A and Ellis, M.D. Impact behaviour of bonded mild steel lap joints. Int. J. of Adhesion and Adhesives. 4 (1984) 13-16.

[9] Harris, J.A. and Adams, R.D. An assessment of the impact performance of bonded joints for use in high energy absorbing structures. Proc. of the Inst. of Mech. Eng. 199 (1985) 121-131.

[10] Goglio, L and Rossetto, M. Strength of adhesive joints under impact stress conditions. In ASME Conference on Engineering Systems Design and Analysis. (2006) Turin. 
[11] Malvade, I, et al. Numerical prediction of load-displacement behaviours of adhesively bonded joints at different extension rates and temperatures. Comput. Mater. Sci. 44 (2009) 1208-1217.

[12] Xiaocong, He. A review of finite element analysis of adhesively bonded joints. Int. J. of Adhesion and Adhesives. 31 (2011) 248-264.

[13] Pandya, K.C. and Williams, J.G. Cohesive zone modelling of crack growth in polymers. Part 1 Experimental measurement of cohesive law. Plastics, Rubber and Composites. 29 (2000) 439445.

[14] Pandya, K.C., Ivankovic, A. and Williams, J.G. Cohesive zone modelling of crack growth in polymers. Part 2 - Numerical simulation of crack growth. Plastics, Rubber and Composites. 29 (2000) 447-452.

[15] Liljedahl, C.D.M. et al. Damage modelling of adhesively bonded joints. Int. J. of Fract. 141 (2006) 147-161.

[16] Sun, C, et al. Rate effects for mixed-mode fracture of plastically-deforming adhesively-bonded structures. Int. J. of Adhesion and Adhesives. 29 (2009) 434-443.

[17] Pirondi, A. and Moroni, F. Simulation of mixed mode I/II fatigue crack propagation in adhesive joints with a modified cohesive zone model. J. of Adhesion Sci. and Tech. 25 (2011) 24832449.

[18] Crocombe, A.D. et al. Predicting the residual strength for environmentally degraded adhesive lap joints. Int. J. of Adhesion and Adhesives. 26 (2006) 325-336.

[19] Clarke, M.I. High Strain Rate Modelling of Adhesive Bonded Joints. [PhD Thesis]. Oxford Brookes University. (2008).

[20] Clarke, M.I., et al. An Investigation into the Use of an Embedded Process Zone Model for Predicting the Structural Behaviour of Adhesive Bonded Joints. Int. J. of Vehicle Struct. and Syst. 3 (2011) 203-209.

[21] Dow Autmotive. Betamate 4601 Structural Adhesive. Technical Datasheet.

[22] Wilson, I., Hartman, N.P. and Sheasby, P.G. Pretreatment for bonded aluminium structures. Adv. Mater. and Process. 152 (1997) 26-29.

[23] British Standards International. BS EN 485:2008 Aluminium and aluminium alloys - Sheet, strip and plate, BSi, (2008).

[24] British Standards International. BS EN ISO 1465:2009 Adhesives. Determination of tensile lapshear strength of bonded assemblies, BSi, (2009).

[25] Dassault Systèmes Simulia Corp. Abaqus/CAE User's Manual. Providence, RI, (2010).

[26] Steidler, S.M., Durodola, J and Beevers, A. Modelling of adhesive bonded joints in vehicle substructures. Int. J. of Mater. and Prod. Technol. 14 (1999) 467-475.

[27] NIST/SEMATECH. Engineering Statistics Handbook [Online] [Accessed 23 January 2012.]. Available from: http://www.itl.nist.gov/div898/handbook/index.htm. 